\title{
AN ALTERNATIVE BALLISTIC LIMIT EQUATION FOR THE WHIPPLE SHIELD IN THE SHATTER REGIME, BASED ON CHARACTERISTICS OF THE LARGE CENTRAL FRAGMENT
}

\author{
Ken Wen ${ }^{1,2 \#}$ (iD) 0000-0002-3010-800X \\ De-ning $\mathrm{Di}^{1 \#}$ (iD 0000-0002-6699-5157 \\ Xiao-wei Chen $^{1,3^{*}}$ (i) 0000-0001-9756-5232 \\ ${ }^{1}$ State Key Laboratory of Explosion Science and Technology, Beijing Institute of Technology, \\ 5th South Zhongguancun Street, 100081, Beijing, China \\ ${ }^{2}$ Institute of Systems Engineering, China Academy of Engineering Physics, \\ Mianyang, Sichuan, 621999, China \\ ${ }^{3}$ Advanced Research Institute of Multidisciplinary Science, Beijing Institute of Technology, \\ 5th South Zhongguancun Street, 100081, Beijing, China \\ \# Ken Wen and De-ning Di contributed equally to this work \\ *chenxiaoweintu@bit.edu.cn
}

\begin{abstract}
In the shatter regime of a Whipple shield, a large central fragment makes a significant contribution to the damage-causing capacity of the debris cloud. Herein we present a feasible scheme for the identification and measurement of this large central fragment and propose an alternative approach to the ballistic limit equation (BLE) for the Whipple shield, deducing an alternative ballistic limit in the shatter regime based on the large central fragment's characteristics. This alternative BLE is compared with the phenomenological Whipple BLE, the JSC Whipple BLE and the Ryan curve. Our alternative BLE, modified at the incipient fragmentation and completed fragmentation point, is shown to agree well with experimental results.
\end{abstract}

Keywords: Whipple shield, debris cloud, ballistic limit equation, large central fragment, fragment identification

Type of the work: Research Article

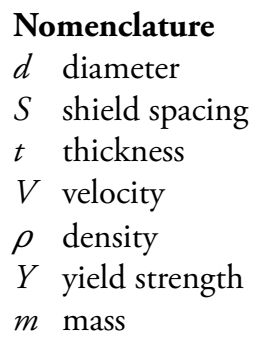

$E_{\mathrm{k}}$ kinetic energy

$C$ sound speed

Subscripts

b bumper

p projectile

f fragment

w witness plate

c critical 


\section{INTRODUCTION}

The Whipple shield and its subsequent improvements have been widely used to protect spacecraft from the impact of orbital debris and micrometeoroids [1]. The general scheme is that after a projectile (orbital debris) impacts the first-layer plate (bumper) of the Whipple shield at an extremely high velocity, it breaks into a debris cloud whose capacity to cause damage is significantly lower than that of the initial projectile. However, the debris cloud does continue to impact the second-layer plate (witness plate) and the wall of the spacecraft. The protection performance of the Whipple shield is defined quantitatively by the ballistic limit equation (BLE). Although various novel structures have been discussed in the literature [2][3] (such as the honeycomb sandwich panel), herein we will focus on metal Whipple structures.

The BLE for the Whipple shield, which has been investigated experimentally and analytically [4] [5], is usually divided into three regimes [6]: the low velocity regime $(<3.0 \mathrm{~km} / \mathrm{s})$, the hypervelocity regime $(>7.0 \mathrm{~km} / \mathrm{s})$ and the shatter regime $(3.0 \mathrm{~km} / \mathrm{s}-7.0 \mathrm{~km} / \mathrm{s})$. In the shatter regime, the debris cloud usually has a remnant large central fragment, which greatly contributes to the cloud's damage-causing capacity. To properly discuss the ballistic limit of the Whipple shield in the shatter regime, in our view, greater attention needs to be paid to this large central fragment.

The importance of the large central fragment has been emphasized in certain extant works. In the debris cloud model proposed by Schafer [7], the large central fragment was set at the front of the internal structure. Cohen [8] assumed that the cratering depth of the debris cloud is a combination of the penetration of the large fragment and the other fragments. Ding et al. [9] calculated the cratering depth by taking the mass fraction of each fragment into consideration. Francesconi et al. [10] stated that the large central fragment is also significant for impact on the sandwich plane. Furthermore, Ryan et al. [6] evaluated shield performance in the shatter regime and concluded that an accurate reflection of the shield's performance could be provided by considering the large central fragment. However, quantitative comparison of the damage-causing capacity of the large central fragment relative to the entire debris cloud in the shatter regime remains scarce.

In the present study, the damage-causing capacities of the large central fragment and the entire debris cloud are compared directly, and we propose an alternative approach to the BLE in the shatter regime based on the large central fragment. In Section 2, the scheme of fragment identification and measurement is developed. In Section 3, the characteristics of the large central fragment under different impact conditions are obtained. In Section 4, an alternative approach to the BLE based on the large central fragment is proposed, and the classic BLEs are introduced. In Section 5, the performance of the alternative BLE is discussed and compared with classic BLEs. Section 6 presents a brief conclusion. Overall, it is hoped that the work presented herein contributes to the further refinement of the BLE in the shatter regime.

\section{FRAGMENT IDENTIFICATION AND MEASUREMENT IN SMOOTHED PARTICLE HYDRODYNAMICS (SPH)}

The dimension and velocity of the large central fragment are required to evaluate its damage-causing capability. This information has been acquired experimentally through the craters and holes on the witness plates[6][11], but such experimental data was limited quantitatively. In the present work, the dimension, velocity, mass and kinetic energy of the large central fragment were measured through a series of AutodynSPH simulations. SPH is a Lagrangian meshless method, which has been widely used to simulate impact and explosion events. 


\subsection{Simulation set-ups}

The impacts between a spherical projectile of Al 2017-T4 and a thin bumper of Al 2A12 were simulated, as shown in Figure 1. Al 2017-T4 was described using the shock equation of state and the Johnson-Cook Strength model, whereas Al 2A12 was described with the shock equation of state and the Steinberg-Guinan Strength model. The material parameters are listed in Tables 1 and 2, respectively. The failure criterion of the Grady Spall model was adopted, with a critical strain of 0.15 . The reliability of the material models was verified [12][13][14]. A stochastic factor was adopted to reflect the inherent flaws of the materials.

Table 1. Material parameters of $\mathrm{Al}$ 2017-T4.

\begin{tabular}{ll}
\hline Properties & $\mathrm{Al}$ 2017-T4 \\
\hline Density, g/cm ${ }^{3}$ & 2.790 \\
Reference temperature, K & 300.00 \\
Specific heat, J/kg.K & 875.00 \\
Grüneisen parameter & 2.00 \\
Parameter C1, m/s & 5370.00 \\
Parameter S1 & 1.29 \\
Parameter quadratic S2 & 0.00 \\
Shear modulus, MPa & 27600.00 \\
Initial yield stress A, MPa & 270.00 \\
Harding constant B, MPa & 426.00 \\
Strain rate constant C & 0.15 \\
Harding exponent $\mathrm{n}$ & 0.34 \\
Thermal softening exponent m & 1.00 \\
Melting temperature, K & 775.00 \\
\hline
\end{tabular}

Table 2. Material parameters of $\mathrm{Al} 2 \mathrm{~A} 12$

\begin{tabular}{ll}
\hline Properties & $\mathrm{Al} 2 \mathrm{~A} 12$ \\
\hline Density, $\mathrm{g} / \mathrm{cm}^{3}$ & 2.784 \\
Reference temperature, K & 300.00 \\
Specific heat, J/kg.K & 850.00 \\
Grüneisen parameter & 2.00 \\
Parameter C1, m/s & 5370.00 \\
Parameter S1 & 1.29 \\
Parameter quadratic S2 & 0.00 \\
Shear modulus, MPa & 28600.00 \\
Initial yield stress, MPa & 325.00 \\
Maximum yield stress, MPa & 760.00 \\
Hardening constant & 310.00 \\
Hardening exponent & 0.185 \\
Derivative dG/dP & 1.865 \\
Derivative dG/dT, $\mathrm{kPa} / \mathrm{K}$ & -17620.00 \\
Derivative dY/dP & 0.017 \\
Melting temperature, K & 1220.00 \\
\hline
\end{tabular}




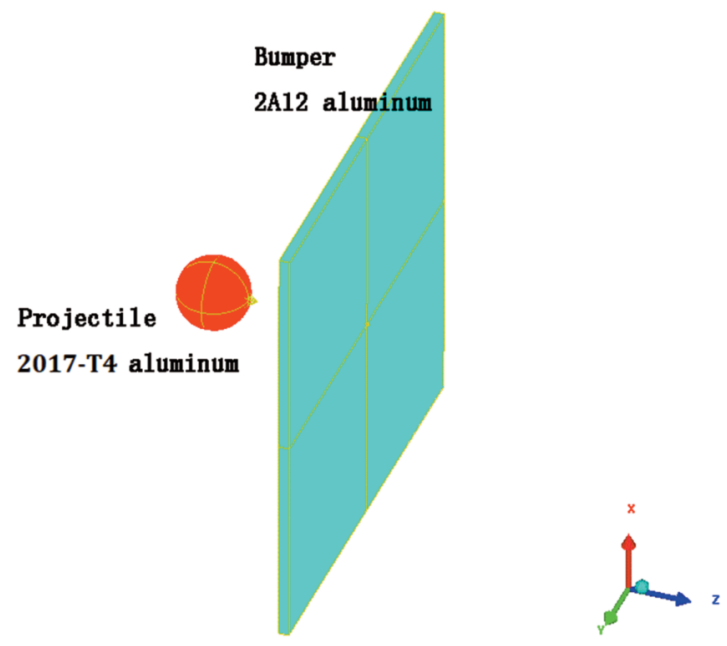

Fig. 1. SPH simulation of a hypervelocity impact.

The fragmentation in SPH is affected by the particle size. Generally, the smaller the particle size, the higher the calculation consumption and the greater the accuracy of fragment information. A particle size of $0.01 \mathrm{~mm}$ was chosen, for which the fragment information is stabilized. A parallel algorithm based on Platform MPI was adopted to improve the calculation efficiency.

In the SPH simulation, a set of discrete points construct the calculation zones. Since there is no mesh between the points, extra work is necessary to identify fragments in the debris cloud. One approach to identifying fragments has been implemented in Autodyn, involving the following steps: judge the state of points from the failure criterion; connect the adjacent failed points to build the edges of the fragments; proceed with the identification of fragments. The number of points included in the fragment, the initial and current location, the velocity and the mass of the fragment were tabulatable in Autodyn. However, the dimensions of the fragment are not accessible.

It is difficult to obtain the dimension of such fragments. Some automation methods of fragment identification in SPH simulation were discussed by Zhang et al. [15] and Liang et al. [16]. These methods relied on several technical algorithm and artificial parameters. A scheme of fragment identification and measurement based on the postprocessing of Autodyn is presented herein.

\subsection{Fragment identification and measurement}

Three cases were selected here to exemplify the scheme of fragment identification and measurement. In these cases, a sphere $6.35 \mathrm{~mm}\left(d_{\mathrm{p}}=6.35 \mathrm{~mm}\right)$ in diameter impacted onto the thin bumper along the Z-axis. Such cases had been experimentally investigated by Chi [12]. The impact conditions are listed in Table 3.

Table 3. Three cases to exemplify the measurement scheme.

\begin{tabular}{lll}
\hline Cases & Bumper thickness $t_{\mathrm{b}}(\mathrm{mm})$ & Impact velocity $V_{\mathrm{p}}(\mathrm{km} / \mathrm{s})$ \\
\hline $1-01$ & 0.50 & 4.24 \\
$1-02$ & 0.50 & 5.00 \\
$1-03$ & 1.00 & 4.25 \\
\hline
\end{tabular}


Figure 2 (1) shows the $2 \mathrm{D}$ projected image of the simulated debris cloud at $20.0 \mu$ s after the collision of case 1-01. Figure 2 (2) is the damage to the experimental witness plate of case 1-01, where the distance between the front plate and the witness plate was $350.00 \mathrm{~mm}$ [12]. The distance was large enough for the fragments to spread. The distribution of the fragments in the simulation agreed well with the distribution of the holes in the experiment, qualitatively. A large central fragment of the debris cloud corresponded to the central hole in the witness plate. A series of fragments with similar dimensions in the outer ring of the debris cloud corresponded to the annular holes around the center of the witness plate.

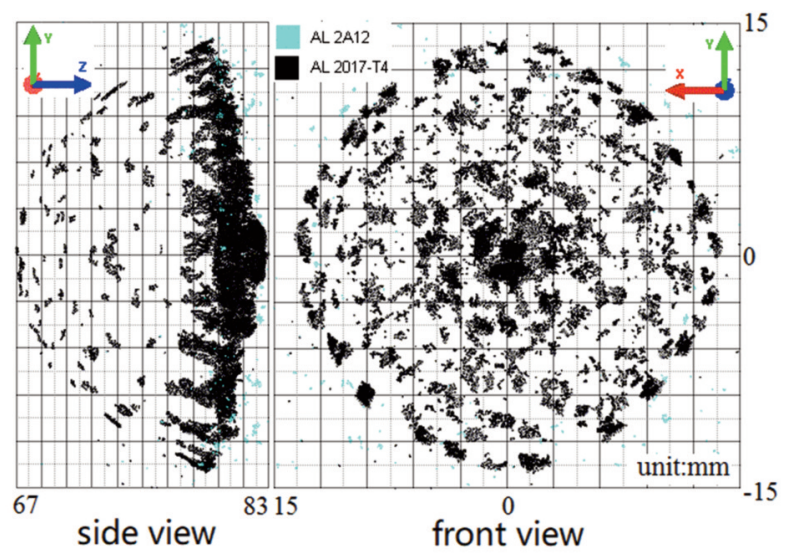

(1)

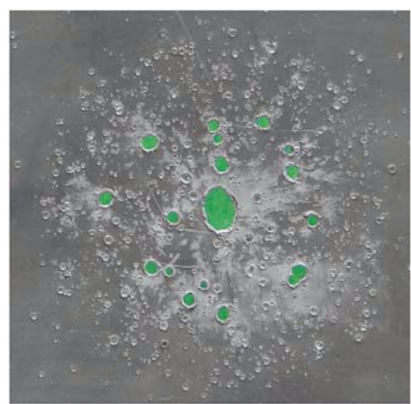

damage of witness plate

(2)

Fig. 2. Comparison of simulated fragments and experimental witness plate [12] for case 1-01 $\left(t_{\mathrm{b}}=0.50 \mathrm{~mm}\right.$, $V_{\mathrm{p}}=4.24 \mathrm{~km} / \mathrm{s}$ ).

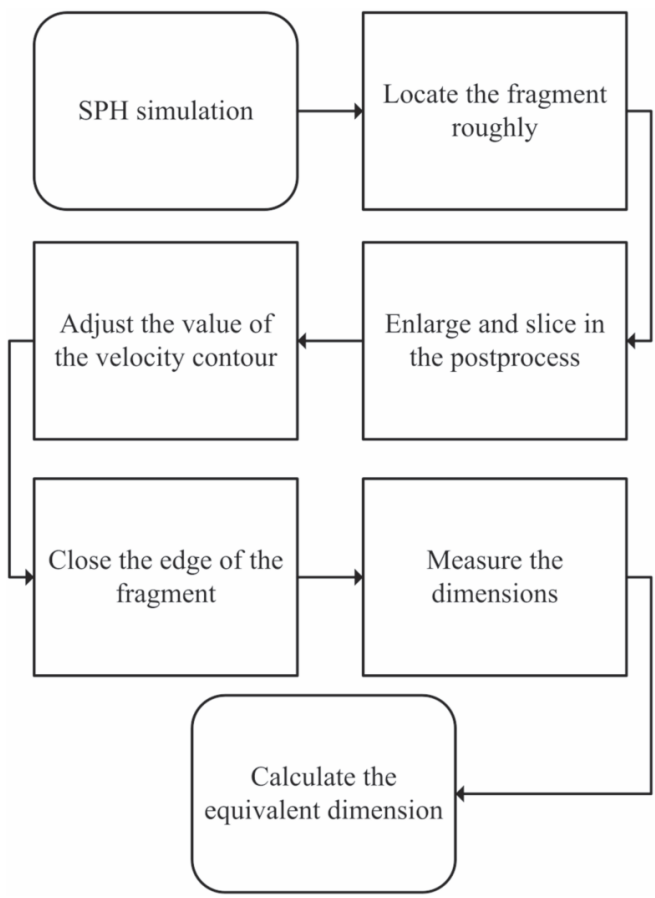

Fig. 3. Scheme of fragment identification and measurement based on Autodyn postprocessing. 
The identification and measurement process is sketched out in Figure 3. First, the fragment is roughly located according to the fragment information provided by Autodyn. Second, the zone around the fragment is sliced and magnified with postprocessing tools. Third, the velocity contour image is displayed, where the independent fragments could be distinguished through their different velocities as shown in Figure 4. Forth, the threshold values of the velocity contour should be adjusted along with the adjustment of the local enlargement view. Fifth, the dimensions are measured. The equivalent diameter of the fragment $d_{\mathrm{f}}$ was

$$
d_{\mathrm{f}}=\sqrt[3]{H W T}
$$

where $H, W$ and $T$ are the fragment's dimensions in the $\mathrm{X}, \mathrm{Y}$ and $\mathrm{Z}$ directions, respectively.

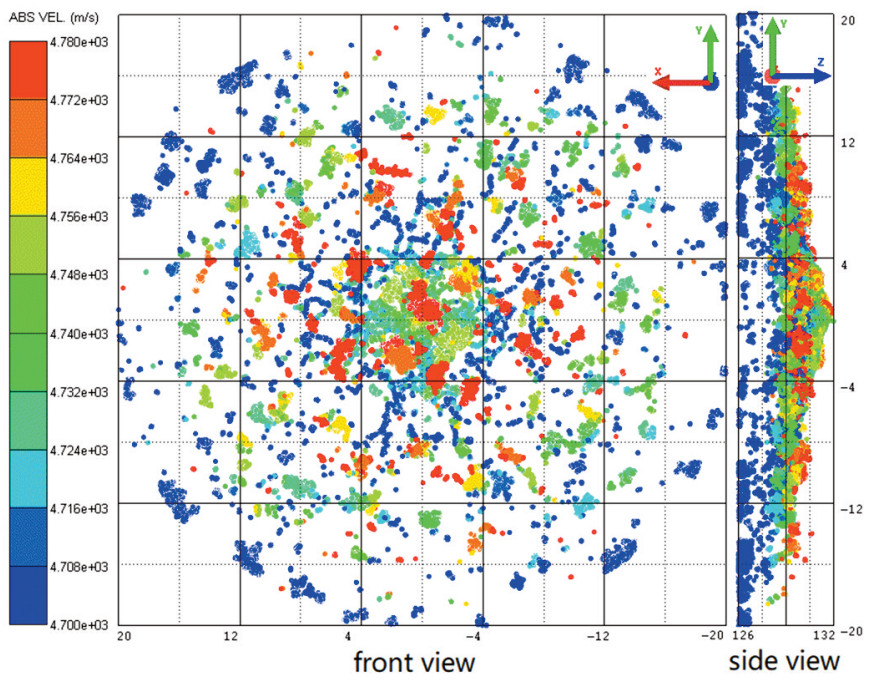

Fig. 4. The velocity contour image of the debris cloud of case 1-02 $\left(t_{\mathrm{b}}=0.50 \mathrm{~mm}, V_{\mathrm{p}}=5.00 \mathrm{~km} / \mathrm{s}\right)$.

The identification and measurement results of the three exemplified cases are shown in Figure 5. The large central fragments are marked by the black rhombus. The equivalent dimensions of the large central fragments obtained through the above scheme are shown in Table 4, compared with the experimental central fragment diameters measured by Chi [12]. The equivalent dimensions of the large fragment obtained numerically and experimentally were consistent. 

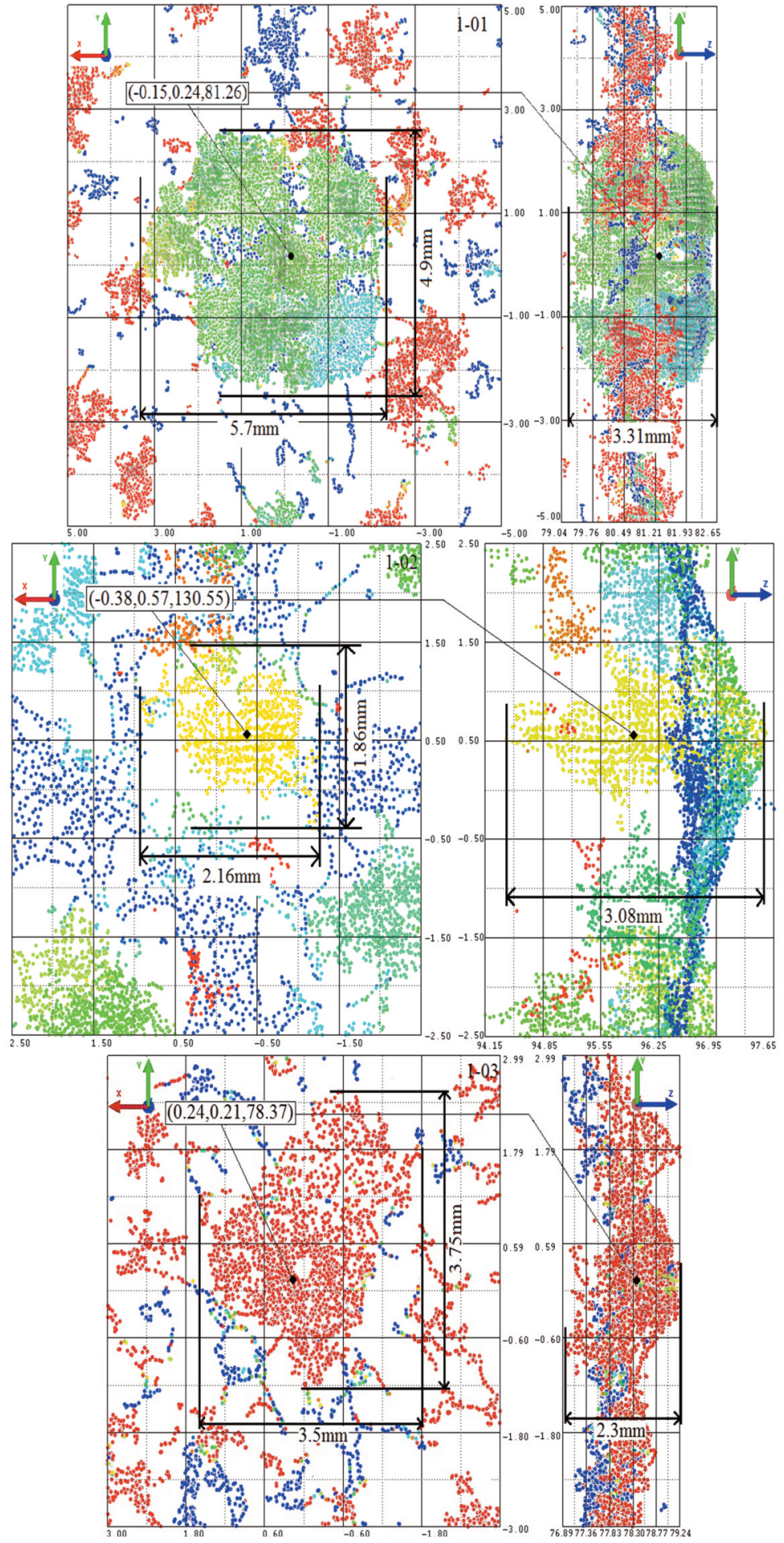

Fig. 5. Boundaries and dimensions of the large central fragments in tests 1-01 1-03. 
Table 4. Equivalent dimensions of the large central fragment in the simulation and experiment [12].

\begin{tabular}{lllll}
\hline Cases & $H, W, T(\mathrm{~mm})$ & $d_{\mathrm{f}}(\mathrm{mm})$ & Experimental $(\mathrm{mm})$ & Error \\
\hline $1-01$ & $5.70,4.90,3.31$ & 4.52 & 4.67 & $-3.18 \%$ \\
$1-02$ & $2.16,1.86,3.08$ & 2.31 & 2.15 & $7.58 \%$ \\
$1-03$ & $3.50,3.75,2.30$ & 3.11 & 3.35 & $-7.05 \%$ \\
\hline
\end{tabular}

\section{CHARACTERISTICS OF THE LARGE CENTRAL FRAGMENT}

The large central fragments of 26 simulation tests were measured through the above scheme. The results are shown in Table 5, where cases 1-01 1-03 were included (case 1-01 to test 2-04, case 1-02 to test 2-07, case 1-03 to test 2-14). The projectile diameter was kept constant $\left(d_{\mathrm{p}}=6.35 \mathrm{~mm}\right)$, while the bumper thicknesses varied from $0.50 \mathrm{~mm}$ to $1.50 \mathrm{~mm}$. The impact velocity ranged from $3.50 \mathrm{~km} / \mathrm{s}$ to $5.50 \mathrm{~km} / \mathrm{s}$.

Table 5. Set-ups for tests 2-01-2-26 and the fragment characteristics.

\begin{tabular}{|c|c|c|c|c|c|}
\hline Tests & $t_{\mathrm{p}}(\mathrm{mm})$ & $V_{\mathrm{p}}(\mathrm{km} / \mathrm{s})$ & $d_{\mathrm{f}}(\mathrm{mm})$ & $m_{\mathrm{f}}(\mathrm{mg})$ & $V_{\mathrm{f}}(\mathrm{km} / \mathrm{s})$ \\
\hline $2-01$ & 0.50 & 3.50 & 6.31 & 258.23 & 3.2750 \\
\hline $2-02$ & 0.50 & 3.75 & 5.64 & 131.10 & 3.5131 \\
\hline $2-03$ & 0.50 & 4.00 & 5.39 & 67.50 & 3.7762 \\
\hline $2-04$ & 0.50 & 4.24 & 4.77 & 56.15 & 4.0152 \\
\hline $2-05$ & 0.50 & 4.50 & 3.67 & 52.40 & 4.2652 \\
\hline $2-06$ & 0.50 & 4.75 & 3.09 & 52.27 & 4.5065 \\
\hline $2-07$ & 0.50 & 5.00 & 2.31 & 41.45 & 4.7511 \\
\hline $2-08$ & 0.50 & 5.50 & 1.73 & 24.41 & 5.2441 \\
\hline 2-09 & 0.50 & 6.00 & 1.30 & 8.41 & 5.7875 \\
\hline $2-10$ & 0.80 & 4.00 & 4.26 & 39.05 & 3.6662 \\
\hline $2-11$ & 1.00 & 3.00 & 4.96 & 129.20 & 2.5847 \\
\hline $2-12$ & 1.00 & 3.50 & 4.19 & 41.14 & 3.1032 \\
\hline $2-13$ & 1.00 & 4.00 & 3.28 & 22.17 & 3.5857 \\
\hline $2-14$ & 1.00 & 4.25 & 3.11 & 20.45 & 3.8152 \\
\hline $2-15$ & 1.00 & 4.50 & 2.63 & 19.39 & 4.0538 \\
\hline $2-16$ & 1.00 & 5.00 & 1.86 & 14.27 & 4.5265 \\
\hline $2-17$ & 1.00 & 5.50 & 1.49 & 4.82 & 5.0330 \\
\hline $2-18$ & 1.20 & 4.00 & 2.72 & 17.25 & 3.4939 \\
\hline $2-19$ & 1.50 & 2.75 & 5.03 & 249.00 & 2.1761 \\
\hline $2-20$ & 1.50 & 3.00 & 4.18 & 32.90 & 2.4347 \\
\hline $2-21$ & 1.50 & 3.25 & 3.50 & 26.52 & 2.6590 \\
\hline $2-22$ & 1.50 & 3.50 & 3.13 & 16.18 & 2.8984 \\
\hline $2-23$ & 1.50 & 4.00 & 2.30 & 13.16 & 3.3590 \\
\hline $2-24$ & 1.50 & 4.50 & 1.82 & 3.16 & 3.9019 \\
\hline $2-25$ & 1.50 & 5.00 & 1.19 & 1.76 & 4.3379 \\
\hline $2-26$ & 1.50 & 5.50 & 1.01 & 0.75 & 4.7790 \\
\hline
\end{tabular}




\subsection{Equivalent dimension of the large central fragment}

Figure 6 shows the equivalent dimensions of the large central fragment at various impact velocities and bumper thicknesses. With increasing impact velocity and/or bumper thickness, the projectile fragmentation increases, and the dimension of the large central fragment decreases.

Dimensional analysis was used to determine the form of the equivalent dimension of the large central fragment. The impact velocity and bumper thickness were assumed as decoupled. The fragment dimension and bumper thickness were normalized with the projectile diameter $d_{\mathrm{p}}$, while the impact velocity was normalized with the initial sound speed of the projectile material $C_{\mathrm{p}}$. The function form is:

$$
\frac{d_{\mathrm{f}}}{d_{\mathrm{p}}}=C_{1}\left(\frac{V_{\mathrm{p}}}{C_{\mathrm{p}}}\right)^{C_{2}}\left(\frac{t_{\mathrm{b}}}{d_{\mathrm{p}}}\right)^{C_{3}},
$$

where $d_{\mathrm{f}}$ is the equivalent dimension of the large central fragment, and $C_{1} \sim C_{3}$ are artificial parameters to be fitted.

Sokolov et al. [17] argued that the size of the large central fragment depends on the impact velocity and the fragmentation initial velocity. Furthermore, Ding et al. [9] posited the equivalent dimension as:

$$
\frac{d_{\mathrm{f}}}{d_{\mathrm{p}}}=C_{4}\left(\frac{V_{\mathrm{p}}}{V_{\mathrm{c}}}\right)^{C_{5}}
$$

where $V_{\mathrm{c}}$ is the critical fragmentation initial velocity, $\mathrm{C}_{4}$ and $\mathrm{C}_{5}$ are artificial parameters to be fitted. Based on the experimental results, Piekutowski [11] suggested that

$$
V_{\mathrm{c}}=1.436\left(\frac{t_{\mathrm{b}}}{d_{\mathrm{p}}}\right)^{-0.333} \mathrm{~km} / \mathrm{s} .
$$

when Equation (4) is substituted into Equation (3), the obtained equation has the same form as Equation (2). Because Equation (2) had fewer presumptions, however, it was adopted for our purposes in this work.

After fitting the measurement data in Table 5, the empirical equation for the dimension of the large central fragment can be expressed as:

$$
\frac{d_{\mathrm{f}}}{d_{\mathrm{p}}}=0.07597\left(\frac{V_{\mathrm{p}}}{C_{\mathrm{p}}}\right)^{-2.4528}\left(\frac{t_{\mathrm{b}}}{d_{\mathrm{p}}}\right)^{-0.6519} .
$$

The standard error of the constant was 0.1370 . The standard error of the exponent of the impact velocity was 0.1396 . The standard error of the exponent of the bumper thickness was 0.0621 . The fitted curves have also been plotted as dash lines in Figure 6.

The absolute value of the exponent of the impact velocity is larger than that of the bumper thickness, which indicates that the impact velocity has a greater influence on the fragment dimension. 


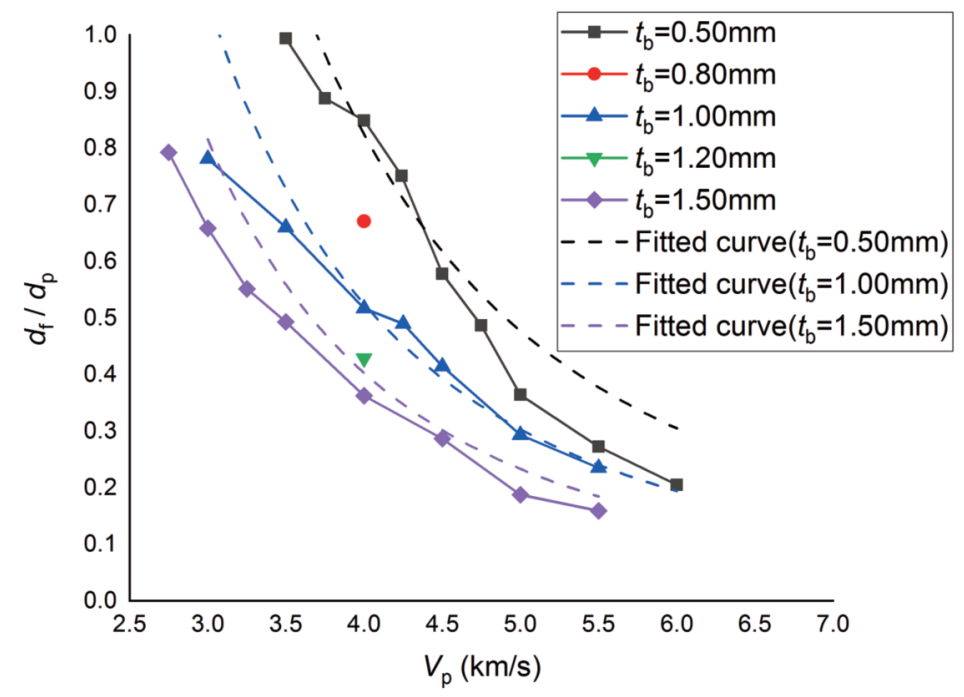

Fig. 6. Equivalent dimension of the large central fragment.

\subsection{Velocity of the large central fragment}

The dimensionless velocity $V_{\mathrm{f}} / V_{\mathrm{p}}$ of the large central fragment at different impact conditions is shown in Figure 7. The dimensionless velocity of the large central fragment increases with increasing impact velocity. With the increasing bumper thickness, the dimensionless velocity of the large central fragment decreases nearly linearly, which is identical to the experimental results [11].

The velocity data was fitted into an equation similar to Equation (2). The dimensionless velocity of the large central fragment, $V_{\mathrm{f}} / V_{\mathrm{p}}$, is expressed as:

$$
\frac{V_{\mathrm{f}}}{V_{\mathrm{p}}}=0.7610\left(\frac{V_{\mathrm{p}}}{C_{\mathrm{p}}}\right)^{0.1027}\left(\frac{t_{\mathrm{b}}}{d_{\mathrm{p}}}\right)^{-0.0950} .
$$

The standard error of the constant was 0.0135. The standard error of the exponent of the impact velocity was 0.0138 . The standard error of the exponent of the plate thickness was 0.0062 . The fitted curves have also been plotted as dash lines in Figure 7. 


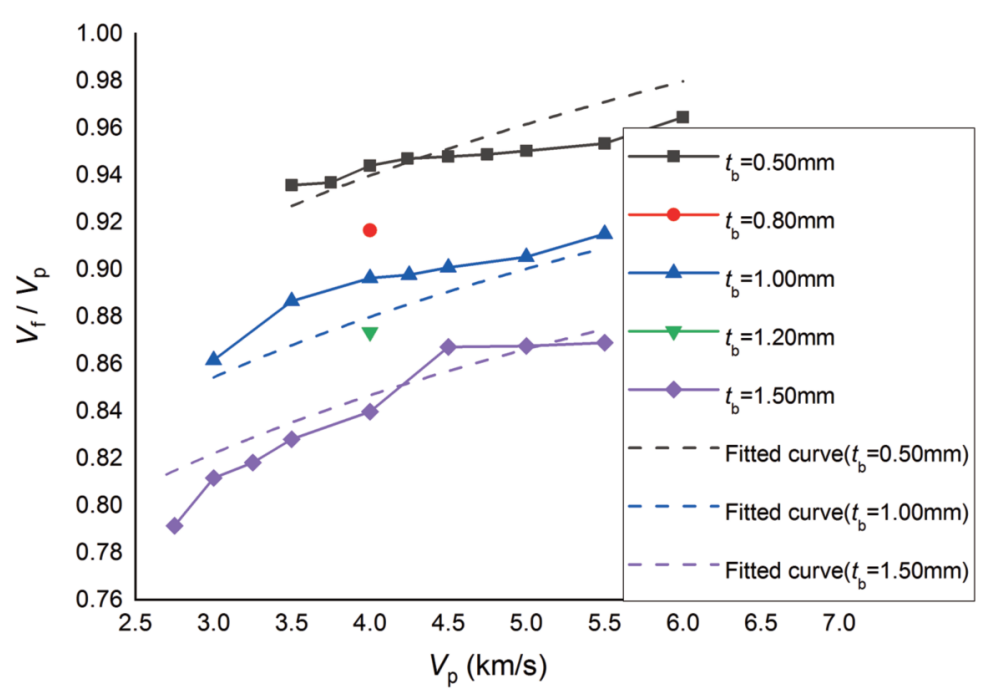

Fig. 7. Dimensionless velocity of the large central fragment.

\subsection{Mass and kinetic energy of the large central fragment}

Figure 8 is the relation between the mass of the large central fragment $\left(m_{\mathrm{f}}\right)$ and the impact velocity. As shown in Figure 8, with increasing impact velocity, the fragment mass decreases rapidly, while the fragment mass is nearly maintained for the medium impact velocities. With the continuously increasing impact velocity, the fragment mass again slightly decreases. The slight downturn following the plateau may be caused by the easier failure induced by the high temperature at high impact velocity. With increasing bumper thickness, the fragment mass decreases gradually.

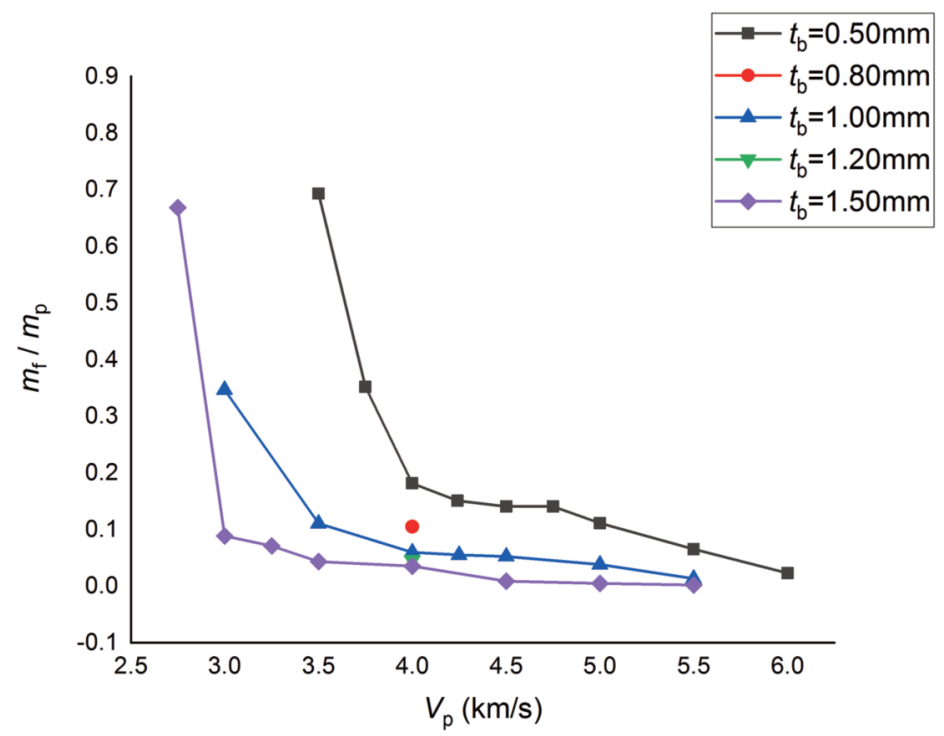

Fig. 8. Mass relationships of the large central fragment versus impact velocity. 
The kinetic energy of the large central fragment $\left(E_{\mathrm{f}}\right)$ could be calculated with the mass and the velocity. The kinetic energy of the large central fragment is shown in Figure 9. The kinetic energy of the large central fragment increases overall with decreasing bumper thickness. With increasing impact velocity, the fragment kinetic energy decreases rapidly for relatively low impact velocity. The fragment kinetic energy increases slightly for the medium impact velocity. With further increase of the impact velocity, the fragment kinetic energy slightly decreases again.

The relationship of the fragment mass and kinetic energy could also be analytically obtained, but it was not considered in this paper.

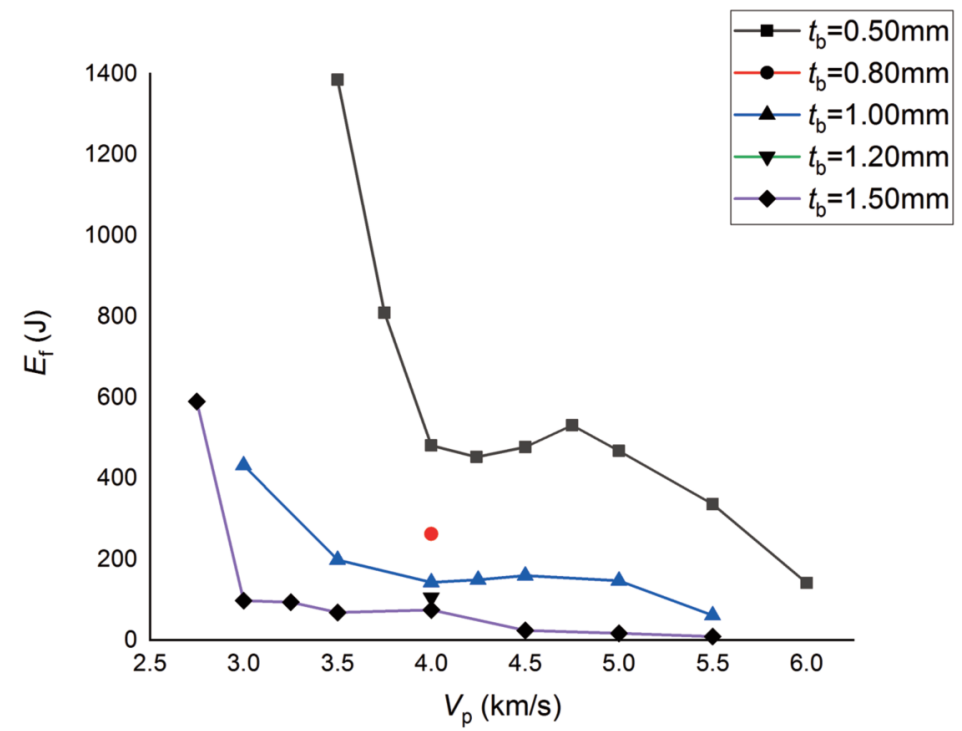

Fig. 9. Kinetic energy relationship of the large central fragment.

\section{WHIPPLE SHIELD BLES}

The large central fragment plays an important role in the debris cloud of the shatter regime. In order to consider the feasibility of using the large central fragment to replace the entire debris cloud when calculating the ballistic limit of Whipple shield, in this section we compare the ballistic limit of the large central fragment, the phenomenological Whipple BLE [18] and the JSC Whipple BLE [6].

\subsection{Ballistic limit of the large central fragment}

The ballistic limit of the large central fragment was deduced based on the penetration equation of a single wall and the characteristics of the large central fragment.

We used the Cour-Palais equation [19] for the penetration of a single projectile onto a single wall, developed in 1985 . With the projectile replaced by the large central fragment and the single wall replaced by the witness plate, the Cour-Palais equation can be expressed as

$$
p=5.24 d_{\mathrm{f}}^{1.056} B H_{\mathrm{w}}^{-0.25} \rho_{\mathrm{p}}^{0.5} \rho_{\mathrm{w}}^{-0.167} E_{\mathrm{w}}^{-0.33} V_{\mathrm{f}}^{0.67},
$$

where $p$ is the penetration depth $(\mathrm{cm}), B H_{\mathrm{w}}$ is the Brinell hardness for the witness plate, $\rho_{\mathrm{p}}$ and $\rho_{\mathrm{w}}$ are the densities of the projectile and witness plate $\left(\mathrm{g} / \mathrm{cm}^{3}\right), E_{\mathrm{w}}$ is Young's modulus of the witness plate (GPa), $d_{\mathrm{f}}$ is the diameter of the large central fragment $(\mathrm{cm}), V_{\mathrm{f}}$ is the velocity of the large central fragment $(\mathrm{km} / \mathrm{s})$. 
If we substitute the large central fragment relationship with initial impact condition (Equations (5) and (6)) into Equation (7) and set the critical thickness $t_{c}$ equal to the penetration depth, then:

$$
t_{\mathrm{c}}=0.2870\left(B H_{\mathrm{w}}^{-0.25} \rho_{\mathrm{p}}^{0.5} \rho_{\mathrm{w}}^{-0.167} E_{\mathrm{w}}^{-0.33} C_{\mathrm{p}}^{2.5213}\right)\left(t_{\mathrm{b}}^{-0.7521} d_{\mathrm{p}}^{1.8081} V_{\mathrm{p}}^{-1.8513}\right) .
$$

It should be emphasized that $t_{\mathrm{b}}$ is the thickness of the bumper impacted by the initial projectile, while $t_{\mathrm{c}}$ is the critical thickness of the witness plate impacted by debris cloud (the large central fragment) in Equation (8). On the right-hand side of Equation (8), the terms in the first bracket are the materials parameters of the projectile and witness plate, while the terms in the second bracket are the initial impact conditions.

With increasing impact velocity and/or bumper thickness, the critical witness plate thickness increases as indicated in Equation (8), which corresponds to the fragmentation of the projectile.

\subsection{Phenomenological Whipple BLE}

Figure 10 is a phenomenological Whipple BLE [18]. Based on the damage types on the witness plate, the phenomenological BLE can be divided into 7 regions, with the variation of the ballistic limit in each region corresponding to changes in the impact phenomena.

In region I, the projectile is intact. The velocity range of Region I is less than $3.1 \mathrm{~km} / \mathrm{s}$. The critical plate thickness increases with the impact velocity. In region II and III, the projectile smashes but remains solid. The downtrend in the critical plate thickness in region II is induced by the energy dispersion of the fragmentation. The velocity range of region II is from $3.1 \mathrm{~km} / \mathrm{s}$ to $4.3 \mathrm{~km} / \mathrm{s}$. After sufficient fragmentation, the increased impact velocity induces an uptrend in the critical plate thickness in region III, until the fragments melt. The velocity range of region III is from $4.3 \mathrm{~km} / \mathrm{s}$ to $5.6 \mathrm{~km} / \mathrm{s}$.

After Region III, molten fragments appear. In region IV, the increased melting of the fragments decreases the critical plate thickness. The velocity range of region IV is from $5.6 \mathrm{~km} / \mathrm{s}$ to $7.0 \mathrm{~km} / \mathrm{s}$. After the sufficient melt, increasing impact velocity induces increased critical plate thickness in region $\mathrm{V}$. The regions after region $\mathrm{V}$ correspond to the vaporization of the projectile. The velocity range after region IV is above $7.0 \mathrm{~km} / \mathrm{s}$.

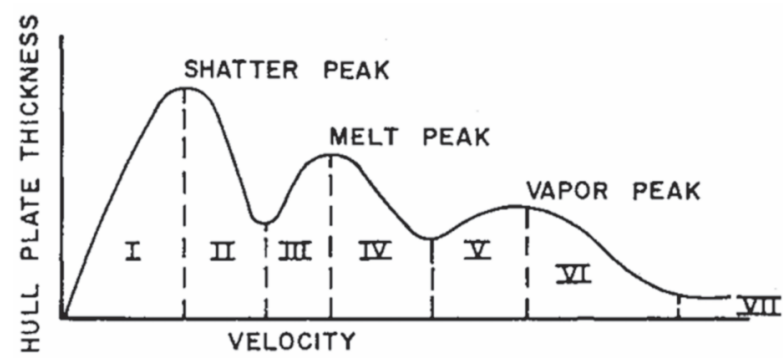

Fig. 10. Phenomenological ballistic limit curve for debris cloud versus impact velocity [18].

\subsection{JSC Whipple BLE}

The JSC Whipple BLE used by Ryan et al. [6] was adopted in this paper, as based on the New Non-Optimum (NNO) BLE [20] and modified again by Reimerdes et al. [21]. The JSC Whipple BLE is defined in 3 regimes. For aluminum materials, the low velocity regime is usually $V_{0} \leq V_{\mathrm{LV}}$, where $V_{\mathrm{LV}}$ depends on $t_{\mathrm{b}} / \mathrm{d}_{\mathrm{p}}$, i.e. $V_{\mathrm{LV}}=2.6 \mathrm{~km} / \mathrm{s}$ if $\left(t_{\mathrm{b}} / d_{\mathrm{p}}\right) \geq 0.16$ and $=1.436\left(t_{\mathrm{b}} / d_{\mathrm{p}}\right)^{-0.33} \mathrm{~km} / \mathrm{s}$ if $\left(t_{\mathrm{b}} / d_{\mathrm{p}}\right)<0.16$. The hypervelocity regime is $V_{0} \geq V_{\mathrm{HV}}=7.0 \mathrm{~km} / \mathrm{s}$. The shatter regime is $V_{\mathrm{LV}}<V_{0}<V_{\mathrm{HV}}$. The linear interpolation of the low regime and the hypervelocity regime is applied to the shatter regime. For the normal impact on a common Whipple shield, the JSC Whipple BLE is expressed as: 


$$
d_{\mathrm{c}}=\left\{\begin{array}{l}
\left(\frac{\left(\frac{Y_{\mathrm{w}}}{40}\right)^{1 / 2} t_{\mathrm{w}}+t_{\mathrm{b}}}{0.6 \rho_{\mathrm{p}}^{1 / 2} V_{\mathrm{p}}^{2 / 3}}\right)^{18 / 19} ; V_{\mathrm{p}} \leq V_{\mathrm{LV}} \\
\left(\frac{\left(\frac{Y_{\mathrm{w}}}{40}\right)^{1 / 2} t_{\mathrm{w}}+t_{\mathrm{b}}}{0.6 \rho_{\mathrm{p}}^{1 / 2} V_{\mathrm{LV}}^{2 / 3}}\right)^{18 / 19}+\left(3.918 F_{2}^{*} \frac{\left(\frac{Y_{\mathrm{w}}}{70}\right)^{1 / 3} V_{\mathrm{HV}}^{-2 / 3} S^{1 / 3} t_{\mathrm{w}}^{2 / 3}}{\rho_{\mathrm{p}}^{1 / 3} \rho_{\mathrm{b}}^{1 / 9}}-\left(\frac{\left(\frac{Y_{\mathrm{w}}}{40}\right)^{1 / 2} t_{\mathrm{w}}+t_{\mathrm{b}}}{0.6 \rho_{\mathrm{p}}^{1 / 2} V_{\mathrm{LV}}^{2 / 3}}\right)^{18 / 19}\right) V_{\mathrm{p}}-V_{\mathrm{LV}} \\
V_{\mathrm{HV}}-V_{\mathrm{LV}}
\end{array} V_{\mathrm{LV}}<V_{\mathrm{p}}<V_{\mathrm{HV}}\right.
$$

where $d_{\mathrm{c}}(\mathrm{cm})$ is the critical projectile diameter in the JSC Whipple BLE, $Y_{\mathrm{w}}(\mathrm{ksi})$ is the yield stress of the witness plate, $S(\mathrm{~cm})$ is the spacing between the witness plate and the bumper. $F_{2}^{*}$ is the de-rating of the shield performance for the hypervelocity regime, which could be calculated as:

$$
F_{2}^{*}=\left\{\begin{array}{l}
1, \text { for }\left(t_{\mathrm{b}} / d_{\mathrm{p}}\right) \geq\left(t_{\mathrm{b}} / d_{\mathrm{p}}\right)_{\mathrm{c}} \\
r_{S / D}-2 \frac{\left(t_{\mathrm{b}} / d_{\mathrm{p}}\right)}{\left(t_{\mathrm{b}} / d_{\mathrm{p}}\right)_{\mathrm{c}}}\left(r_{S / D}-1\right)+\left[\frac{\left(t_{\mathrm{b}} / d_{\mathrm{p}}\right)}{\left(t_{\mathrm{b}} / d_{\mathrm{p}}\right)_{\mathrm{c}}}\right]^{2}\left(r_{S / D}-1\right), \text { for }\left(t_{\mathrm{b}} / d_{\mathrm{p}}\right)<\left(t_{\mathrm{b}} / d_{\mathrm{p}}\right)_{\mathrm{c}}
\end{array}\right.
$$

where $r_{S / D}$ is the ratio between the required rear wall thickness when the bumper thickness is zero, and when it is equal to the limit $\left(t_{\mathrm{b}} / d_{\mathrm{p}}\right)_{\mathrm{c}}$, i.e.:

$r_{S / D}=\frac{t_{\mathrm{w}}\left(t_{\mathrm{b}}=0\right)}{t_{\mathrm{w}}\left(\left(t_{\mathrm{b}} / d_{\mathrm{p}}\right)=\left(t_{\mathrm{b}} / d_{\mathrm{p}}\right)_{\mathrm{c}}\right)}=\frac{\left(0.6 \cdot d_{\mathrm{p}}^{19 / 18}(\cos \theta)^{5 / 3} \rho_{\mathrm{p}}^{1 / 2} V_{\mathrm{HV}}^{2 / 3}-t_{\mathrm{b}}\right) /\left(Y_{\mathrm{w}} / 40\right)^{1 / 2}}{\left(d_{\mathrm{p}} / 3.918 \cdot \rho_{\mathrm{p}}^{-1 / 3} \rho_{\mathrm{b}}^{-1 / 9}\left(V_{\mathrm{HV}} \cos \theta\right)^{-2 / 3} S^{1 / 3}\left(Y_{\mathrm{w}} / 70\right)^{1 / 3}\right)^{3 / 2}}$.

\section{DISCUSSION ABOUT THE ALTERNATIVE BLE FOR WHIPPLE SHIELD}

\subsection{Comparison of the BLEs}

The relevant tests performed by Swift et al. [22] and Ryan et al. [6] were selected as points of reference. In their tests, the Al 6061-T6 bumper thickness $(t=0.079 \mathrm{~cm})$, shield spacing $(S=5.08 \mathrm{~cm})$ and the $\mathrm{Al} 6061-\mathrm{T} 6$ projectile diameter $\left(d_{\mathrm{p}}=0.3175 \mathrm{~cm}\right)$ were constant, while the $\mathrm{Al} 6061-\mathrm{T} 6$ witness plate thickness $\left(t_{\mathrm{w}}\right)$ was varied to determine the shield failure limits. The same material parameters, spacing and bumper thickness were assigned in Equation (8) and Equation (9) to compare their performance.

Figure 11 plots the JSC Whipple BLE (in a reformulation of the wall thickness at constant projectile diameter solved from Equation (9)) and the relevant experimental results. As shown in Figure 11, the experimental impact velocity was limited to $8.0 \mathrm{~km} / \mathrm{s}$. The experimental results agreed well with the first five regions of the phenomenological BLE in Figure 10. The low velocity regime of the JSC Whipple BLE corresponded to Region I of the phenomenological BLE $(<3.0 \mathrm{~km} / \mathrm{s})$. The high velocity regime of the JSC Whipple BLE corresponded to Region V of the phenomenological BLE $(>7.0 \mathrm{~km} / \mathrm{s})$. 
The JSC Whipple BLE combined Regions II, III and IV into the shatter regime with a simplified linear interpolation.

Figure 11 also plots the ballistic limit curve proposed by Ryan et al. [6]. For the ballistic limit between $3.0 \mathrm{~km} / \mathrm{s}$ and $4.3 \mathrm{~km} / \mathrm{s}$ (Region II of the phenomenological BLE), these authors calculated it with the largest fragment relationship proposed by Piekutowski [11]. For the ballistic limit between $4.3 \mathrm{~km} / \mathrm{s}$ to $5.6 \mathrm{~km} / \mathrm{s}$ (Region III of the phenomenological BLE), they calculated it based on the assumption that the largest fragment diameter is constant. Between $2.6 \mathrm{~km} / \mathrm{s}$ and $3.0 \mathrm{~km} / \mathrm{s}$, the Ryan curve was linked to the JSC Whipple BLE by the quadratic Bézier curve. The residual sections $(<2.6 \mathrm{~km} / \mathrm{s}$ or $>5.6 \mathrm{~km} / \mathrm{s})$ of the Ryan curve were described by the JSC Whipple BLE.

The ballistic limit of the large central fragment (Equation (8)) was also plotted in Figure 11. Note that the BLE calculated from the large central fragment was only suitable for the shatter regime, especially between $3.0 \mathrm{~km} / \mathrm{s}$ to about $5.3 \mathrm{~km} / \mathrm{s}$. For the velocity from $2.6 \mathrm{~km} / \mathrm{s}$ to $3.0 \mathrm{~km} / \mathrm{s}$, the ballistic limit was higher than the Ryan curve, which may indicate the inaccuracy of the simulated fragment information at the incipient fragmentation. For the impact velocity from $3.0 \mathrm{~km} / \mathrm{s}$ to $4.3 \mathrm{~km} / \mathrm{s}$, the BLE in this paper was found to be in accordance with the Ryan curve. Another distinction appeared after $4.3 \mathrm{~km} / \mathrm{s}$, where the Ryan curve was based on the assumption of a constant large central fragment. However, the mass of the large central fragment obtained in this paper (Figure 6 and Figure 7) kept decreasing between $4.3 \mathrm{~km} / \mathrm{s}$ to $5.3 \mathrm{~km} / \mathrm{s}$, corresponding to the completed fragmentation region. The difference between the BLE in this paper and the experimental results gradually increases for velocity larger than $5.3 \mathrm{~km} / \mathrm{s}$.

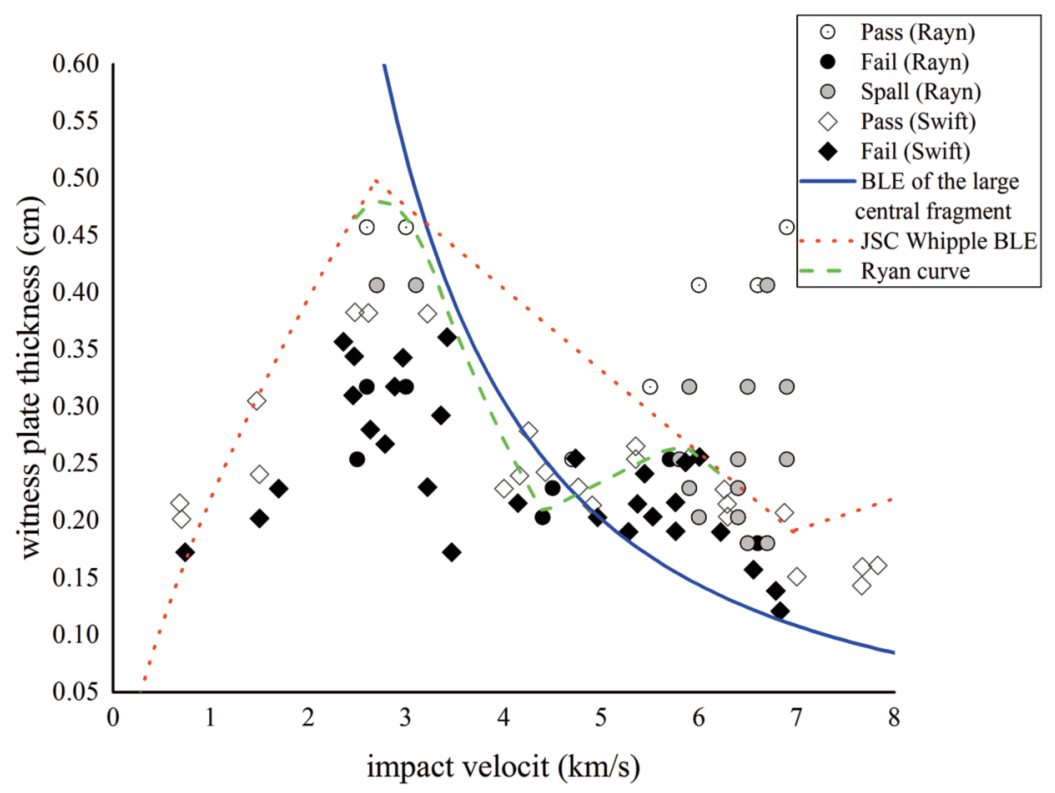

Fig. 11. The BLE of the large central fragment, JSC Whipple BLE [20][21], Ryan curve [6] and relevant experimental results [6][22].

\subsection{Modification of the alternative BLE}

As shown in Figure 11, the JSC Whipple BLE successfully described Regions I and V of the phenomenological BLE, whereas the Ryan curve successfully described Regions II, III and IV. The BLE attempted in this paper was only suitable between $3.0 \mathrm{~km} / \mathrm{s}$ to $5.3 \mathrm{~km} / \mathrm{s}$. 
The damage-causing capacity of the debris cloud is influenced by multiple mechanisms. Increasing impact velocity would result in a higher degree of fragmentation and liquefaction of the projectile and higher velocity of the debris cloud. The damage-causing capacity of the debris cloud would be weakened by a higher degree of fragmentation and liquefaction of the projectile, and strengthened by higher fragment velocity.

In Regions II and III, the performance of the Whipple shield is the result of competition between increasing fragmentation and increasing fragment velocity. In Regions IV and V, in turn, the performance of the Whipple shield is the result of competition between increasing liquefication and increasing fragment velocity.

It is not feasible to evaluate the competition between these mechanisms quantitively. The Ryan curve adopts a referential method: the increasing fragmentation between $3.0 \mathrm{~km} / \mathrm{s}$ to $4.3 \mathrm{~km} / \mathrm{s}$ was evaluated, whereas the increasing fragmentation was ignored between $4.3 \mathrm{~km} / \mathrm{s}$ to $5.6 \mathrm{~km} / \mathrm{s}$ (the mass was assumed as constant in this region); the residual part was linked to the JSC Whipple BLE.

The ballistic limit of the large central fragment was consistent with that of the debris cloud in the main part of the shatter regime. But the comparison in Figure 11 shows that the simulated fragment information was not accurate at the incipient fragmentation $(\approx 3.0 \mathrm{~km} / \mathrm{s})$ and the completed fragmentation $(\approx 4.3 \mathrm{~km} / \mathrm{s})$. Taking the competition mechanism into consideration, the following modification may be proposed: assume that the increasing damage-causing capacity brought by increasing fragment velocity is balanced with the decreasing damage-causing capacity resulting from the increasing degree of fragmentation in the incipient-fragmentation and completed-fragmentation region.

Thus, an alternative method was obtained: The low velocity regime and high velocity regime of the JSC Whipple BLE, and the BLE of the central large fragment were adopted. The BLE of the central large fragment was connected to the tail of the high velocity regime of the JSC Whipple BLE and was connected to the head of the low velocity regime of the JSC Whipple BLE with a horizontal line. The BLE of this alternative method was plotted in Figure 12.

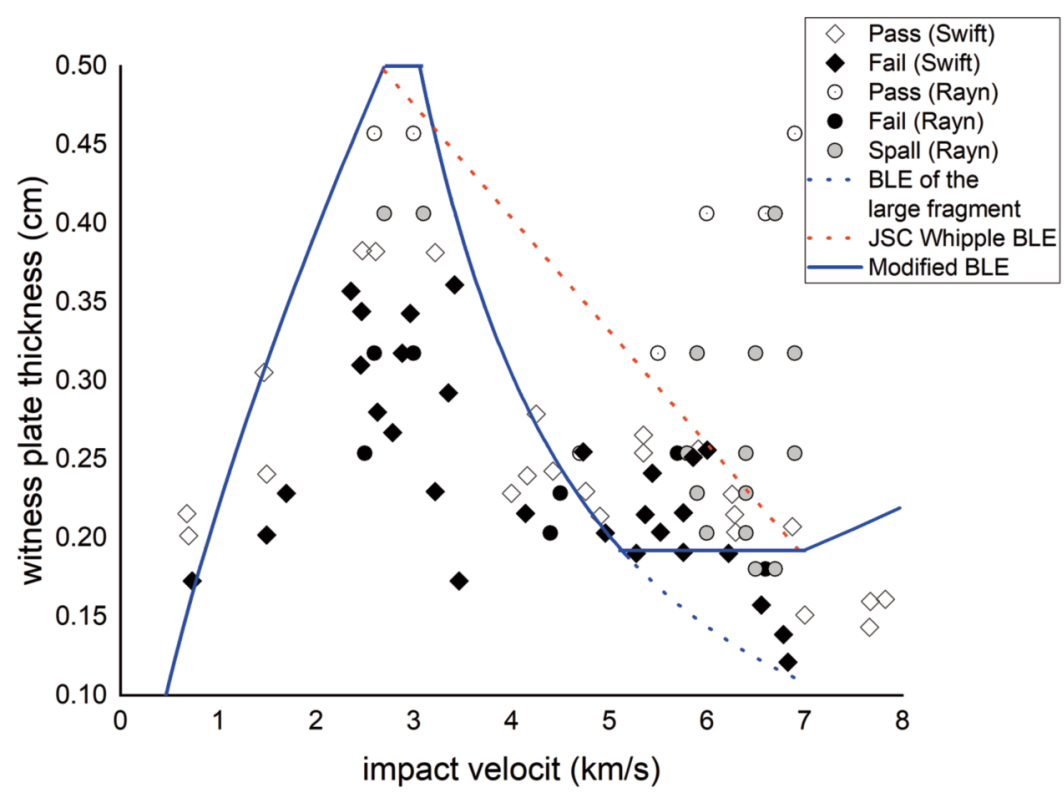

Fig. 12. Alternative BLE based on the large central fragment. 
As shown in Figure 12, the alternative BLE agreed well with the experimental results. The competition mechanism of the damage-causing capacity was simplified. Regions I and V are identical to that of the JSC Whipple BLE, while Regions II, III and IV are described by the BLE of the large central fragment and a horizontal line. The alternative BLE proposed here can be plotted according to Equation (8) and Equation (9). Note that the alternative BLE proposed here is also applicable to Whipple shields with other plate combinations.

\section{CONCLUSIONS}

In this paper, we have devised a fragment identification method to obtain the equivalent dimension, velocity, mass and kinetic energy of the large central fragment in the debris cloud. The empirical equations of these parameters were presented by fitting the identification results.

An alternative approach for the Whipple BLE based on the large central fragment was proposed. This alternative BLE was next compared with the phenomenological Whipple BLE, the JSC Whipple BLE, the Ryan curve and experimental results. The competition mechanism of the damage-causing capacity in the shatter regime was simplified. Combined with the JSC Whipple BLE, this alternative BLE agreed well with experimental results. Although the discussion and analysis herein were developed and validated for aluminum-on-aluminum impacts, the methodology presented can readily be adapted to other material combinations.

\section{Acknowledgments}

This work was supported by the National Natural Science Foundation of China (11872118, 11627901).

\section{REFERENCES}

[1] Whipple F.L., 1947, "Meteorites and space travel," Astronomical Journal, 52, 132-137.

[2] Kang P., Youn S.K. and Lim J.H., 2013"Modification of the critical projectile diameter of honeycomb sandwich panel considering the channeling effect in hypervelocity impact," Aerospace Science and Technology, 29, 413-425.

[3] Zhang X.T., Wang R.Q., Liu J.X., Li X.G. and Jia G.H., 2018, "A numerical method for the ballistic performance prediction of the sandwiched open cell aluminum foam under hypervelocity impact," Aerospace Science and Technology, 75, 254-260.

[4] Cour-Palais B.J., 1969, "Meteoroid protection by multiwall structures," AIAA Hypervelocity Impact Conference, Cincinnati, OH, USA.

[5] Christiansen E.L. and Justin H.K., 2001, "Ballistic limit equations for spacecraft shielding," International Journal of Impact Engineering, 26, 93-104.

[6] Ryan S., Bjorkman M. and Christiansen E.L., 2011, "Whipple shield performance in the shatter regime," International Journal of Impact Engineering, 38, 504-510.

[7] Schafer F.K., 2006, "An engineering fragmentation model for the impact of spherical projectiles on thin metallic plates," International Journal of Impact Engineering, 33, 745-762.

[8] Cohen L.J., 1995, “A debris cloud cratering model," International Journal of Impact Engineering, 17, 229-240.

[9] Ding L., Li C., Pang B. and Zhang B., 2008, "Ballistic limit equations in ballistic and shatter regions," International Journal of Impact Engineering, 35, 1490-1496.

[10] Francesconi A., Giacomuzzo C., Feltrin F., Antonello A. and Savioli L., 2015, "An engineering model to describe fragments clouds propagating inside spacecraft in consequence of space debris impact on sandwich panel structures," Acta Astronautica, 116, 222-228. 
[11] Piekutowski A.J., 1996, Formation and Description of Debris Clouds Produced by Hypervelocity Impact, NAS8-38856.

[12] Chi R., 2010, Research and modeling of debris cloud produced by hypervelocity impact of projectile with thin plate, PhD Thesis, Harbin Institute of Technology, 100-120. (in Chinese)

[13] Wen K., Chen X.W., Chi R.Q. and Lu Y.G., 2020, "Analysis on the fragmentation of sphere hypervelocity impacting on thin plate," International Journal of Impact Engineering, 146, 103721.

[14] Wen K., Chen X.W., 2021, "Failure evolution in hypervelocity impact of Al spheres onto thin Al plates," International Journal of Impact Engineering, 147, 103727.

[15] Zhang X., Jia G. and Huang H., 2011, "Fragment identification and statistics method of hypervelocity impact SPH simulation," Chinese Journal of Aeronautics, 24, 18-24.

[16] Liang S.C., Li Y., Chen H., Huang J. and Liu S., 2013, "Research on the technique of identifying debris and obtaining characteristic parameters of large-scale 3D point set, "International Journal of Impact Engineering, 56, 27-31.

[17] Sokolov V.G., Christiansen E.L., Gorbenko A.V., Feldstein V.A., Romanchenkov V.P., Panichkin N.G., Yachlakov Y.V. and Zinchenko L.V., 2001, "The effect of thin deployable construction elements of the international space station on the probability of its hull penetration by meteoroids and orbital debris, International Journal of Impact Engineering, 26, 725-734.

[18] Hopkins A.K., Lee T.W. and Swift H.F., 1972, "Material phase transformation effects upon performance of spaced bumper systems," Journal of Spacecraft and Rockets, 9(5), 342-345.

[19] Hayashida K.B. and Robinson J.H., 1991, Single wall penetration equations, NASA TM-103565.

[20] Christiansen E.L., 1993, "Design and performance equations for advanced meteoroid and debris shield," International Journal of Impact Engineering, 14, 145-156.

[21] Reimerdesa H.G., Nolke D. and Schafer F., 2006, "Modified Cour-Palais/Christiansen damage equations for double-wall structures," International Journal of Impact Engineering, 33, 645-654.

[22] Swift H., Preonas D., Dueweke P. and Bertke R., 1970, Response of materials to impulsive loading. AFML-TR-70e135. Dayton: Air Force Materials Laboratory, Wright Patterson Air Force Base.

\title{
ALTERNATYWNE RÓWNANIE DO KALKULACJI BALISTYCZNYCH GRANIC TARCZY WHIPPLE'A W „TRYBIE ROZTRZASKANIA”, OPARTE NA CHARAKTERYSTYCE DUŻEGO ODŁAMKA CENTRALNEGO
}

\begin{abstract}
Abstrakt
W tzw. trybie „roztrzaskania” tarczy Whipple'a, duży centralny fragment obiektu zderzeniowego odpowiada za znaczną część ogólnej zdolności chmury odłamków do powodowania zniszczeń. W niniejszym opracowaniu przedstawiono realny schemat identyfikacji i pomiaru tego dużego centralnego fragmentu i na tej podstawie zaproponowano alternatywne podejście do balistycznego równania granicznego (BLE) dla tarczy Whipple'a. Wyznaczono alternatywną graniczną wartość balistyczną w reżimie roztrzaskania na podstawie charakterystyki centralnego fragmentu. Takie alternatywne podejście jest porównane $\mathrm{z}$ fenomenologicznym równaniem dla tarczy Whipple'a, z równaniem JSC Whipple oraz i z tzw. krzywą Ryana. Proponowane alternatywne równanie BLE, zmodyfikowane w punkcie początkowej i końcowej fragmentacji, wykazuje dobry poziom spójności z wynikami eksperymentalnymi.
\end{abstract}

Słowa kluczowe: tarcza Whipple'a, chmura odłamków, balistyczne równanie graniczne, duży fragment centralny, identyfikacja fragmentów 